\title{
Effects of the early social environment on behavioral responses of dairy calves to novel events
}

\author{
A. De Paula Vieira, ${ }^{\star}$ A. M. de Passillé, $†$ and D. M. Weary ${ }^{\star 1}$ \\ *Animal Welfare Program, University of British Columbia, Vancouver, BC, V6T 1Z4, Canada \\ †Pacific Agri-Food Research Centre, AAFC, Agassiz, BC, VOM 1A0, Canada
}

\begin{abstract}
Providing young animals the opportunity to engage in more complex social interactions is hypothesized to improve their capacity to cope with changing environments. To test the effects of the early social environment on the behavioral responses of dairy calves to novelty we compared (1) individual with pair housing and (2) group housing with companions of similar age with group housing with a more experienced conspecific. Fifty-four dairy calves were separated from the cow soon after birth and housed individually $(\mathrm{n}=6$ calves) or in pairs ( $\mathrm{n}=6$ pairs), or in pens composed of groups of 3 young calves ( $\mathrm{n}=6$ groups) or groups of 2 young calves and an older calf ( $\mathrm{n}=6$ groups). At 65 to $69 \mathrm{~d}$ of age, calf responses were tested in an environmental novelty test and a social novelty test. Individually housed calves were more active [i.e., spent less time standing (means \pm SEM): 201.4 vs. $280.3 \pm 30.5$ s/test; and more time running: 83.2 vs. $57.3 \pm 19.1 \mathrm{~s} /$ test] and more reactive (i.e., defecated more frequently; 1.3 vs. $0.6 \pm 0.2$ events/test) when tested in the novel arena, compared with pair-housed calves. During the social novelty test, individually housed calves spent less time running (51.8 vs. $96.4 \pm 11.6 \mathrm{~s} /$ test), showed a longer latency to socially interact (111.1 vs. $20.4 \pm 21.7 \mathrm{~s} /$ test), and spent more time involved in social interactions (130.7 vs. $79.7 \pm 19.0 \mathrm{~s} /$ test) with the unfamiliar calf than did pair-housed calves. Individually housed calves were also more reactive to the presence of an unfamiliar calf as indicated by increased rates of defecation (2.3 vs. $0.7 \pm 0.5$ events/test) and kicking ( 2.2 vs. $0.7 \pm 0.4$ events/test) compared with pair-housed calves. Calves housed in groups with an older companion were more reactive to the novel environment than were calves housed in groups of similar age: they defecated (1.0 vs. $0.6 \pm 0.2$ events/test) and vocalized (23.6 vs. $15.3 \pm 3.8$ events/test) more during the test. These calves also spent less time exploring (266.3 vs.
\end{abstract}

\footnotetext{
Received October 21, 2011.

Accepted May 7, 2012.

${ }^{1}$ Corresponding author: dan.weary@ubc.ca
}

$355.0 \pm 27.4$ events/test) and had a lower frequency of kicking (0.1 vs. $2.0 \pm 0.5$ events/test) when tested with an unfamiliar calf. We conclude that calves housed individually are more reactive to environmental and social novelty when compared with calves housed in pairs and that calves housed with an older companion are less reactive to a novel calf when compared with calves housed in groups of similar age.

Key words: isolation, social bond, social learning, group housing

\section{INTRODUCTION}

In nature, calves' early social interactions are focused on the cow, but as lactation progresses the cow increases the time and distance away from her calf, allowing fewer suckling bouts and terminating these more rapidly (Price, 1985). Initially calves start grazing near the cow (Mirza and Provenza, 1992), but over the first few weeks of life, the calf increasingly distances itself from the dam and interacts with other calves (Vitale et al., 1986; Sato et al., 1987) and older cattle (e.g., Sato et al., 1987; Murphey et al., 2000). In contrast to this complex social environment that calves experience in more natural settings, on many dairy farms calves are separated from the dam soon after birth and housed individually in pens or in hutches.

Providing calves the opportunity to engage in social interactions may allow for the development of better cognitive and social abilities. Research on other species has shown that social isolation of neonates can increase aggressive behavior, increase cognitive errors during discrimination tasks, and decrease brain development and plasticity (e.g., Schrijver and Würbel, 2001; Fowler et al., 2002; Lipkind et al., 2002; Schrijver et al., 2002). Animals that have been reared in social isolation tend to be more reactive, anxious, and emotional and thus are less likely to respond to novel environmental stimuli appropriately than are animals raised with a companion (e.g., Koch and Arnold, 1972; Sahakian et al., 1977).

Existing evidence suggests that early social experiences can influence calf responses to novelty. For example, individually housed calves vocalize more at 
weaning from milk, take longer to learn to use automatic systems, and experience a more severe growth check when moved to a large group pen than do calves housed in pairs (De Paula Vieira et al., 2010). Individually housed calves also show stronger fear responses to novel situations (Jensen et al., 1997). The simplest possible group is a pair of similarly aged calves; thus, the first objective of this study was to test if calf responses to environmental and social novelty are reduced in pairhoused compared with individually housed calves.

Calves may also benefit from access to older social partners, in part because older social companions may provide more salient social cues. In a recent study (De Paula Vieira et al., 2012), we demonstrated that group housing with an older social companion increased solid feed intake preweaning and BW gains before and after weaning; these results suggested that calves housed with an older companion were better able to learn to consume solid feed and this, in turn, improved their responses to weaning from milk when compared with calves housed in groups of a similar age. Thus, the second objective of this study was to test if calf responses to environmental and social novelty are reduced when calves are housed with an older companion compared with housing with a group of similarly aged calves.

\section{MATERIALS AND METHODS}

This study used 54 Holstein dairy heifers housed at the University of British Columbia's (UBC) Dairy Education and Research Centre (Agassiz, BC, Canada). This animal use was approved by UBC's Animal Care Committee.

\section{Pretesting}

Calves were separated from their dams and fed colostrum within $8 \mathrm{~h}$ of birth. To assess the efficiency of passive immune transfer, blood samples were collected from the jugular vein $24 \mathrm{~h}$ after the first feeding of colostrum, and serum was analyzed using a Reichert AR 200 digital hand-held refractometer (Reichert Inc., Depew, NY). Only calves having a serum protein level $>5.5 \mathrm{~g} / \mathrm{dL}$ were included in the study. After colostrum feeding, the umbilical cord was treated with a $7 \%$ iodine solution. Calves were sedated and dehorned at 4 d of age using caustic paste (see Vickers et al., 2005).

Prior to $9 \mathrm{~d}$ of age, all calves were housed individually with free access to water, hay, and starter. Calves were then assigned to 1 of 4 treatments: (1) individual housing ( $\mathrm{n}=6$ calves), (2) pair housing ( $\mathrm{n}=6$ pairs), (3) group housing in groups of 3 young calves ( $\mathrm{n}=$ 6 groups), or (4) group housing in groups of 2 young calves and an older calf ( $\mathrm{n}=6$ groups). Older companions averaged $83 \pm 5.4 \mathrm{~d}$ of age when mixed with the younger calves. Calves were assigned pseudo-randomly to treatment, balancing for BW on d 9. These weights averaged $( \pm \mathrm{SD}) 44.9 \pm 5.6 \mathrm{~kg}$ for individual housing, $44.8 \pm 5.7 \mathrm{~kg}$ for pair housing, $45.9 \pm 5.7 \mathrm{~kg}$ for groups of 3 young calves, and $46.4 \pm 5.8 \mathrm{~kg}$ for the groups of 2 young calves housed with an older companion (weighing, on average, $120.4 \pm 8.3 \mathrm{~kg}$ ).

The individual pen measured $1.2 \times 2.0 \mathrm{~m}$ and the pair pen measured $2.4 \times 2.0 \mathrm{~m}$. Group pens measured $7.0 \times 5.0 \mathrm{~m}$. The older companion calves had lived in the group pens for approximately $10 \mathrm{wk}$ before assigning younger calves to this treatment.

All of the young calves were allowed access to $8 \mathrm{~L} / \mathrm{d}$ of pasteurized whole milk (a mixture of saleable and nonsaleable milk) either by bottle (for calves housed individually and in pairs) or by a CF1000CS-Combi automatic feeder (DeLaval International AB, Tumba, Sweden) that also provided free access to a textured calf starter (for the 2 group treatments). Calves housed individually and in pairs received free access to starter via bucket. The starter offered for all calves (93\% DM) contained $57.5 \%$ concentrate pellets, $14 \%$ flatted barley, $13 \%$ flatted oats, $10 \%$ steamrolled corn, and $3.5 \%$ molasses (Unifeed Ltd., Chilliwack, Canada). All calves had free access to water and chopped orchard grass hay $(95 \% \mathrm{DM})$ with a mean particle size of $1.2 \pm 0.4$ $\mathrm{cm}$ as measured using the Penn State Particle Separator (Pennsylvania State University, University Park). Group-housed calves received water and hay automatically (Insentec BV, Marknesse, the Netherlands), whereas calves housed individually and in pairs received these via water buckets and individual hayracks suspended on the wall of the pen.

Calves were trained by a caretaker to use the bottle and milk feeders. This training was carried out in the morning and afternoon of each of the first $3 \mathrm{~d}$ of the experimental period. Weaning was carried out gradually starting on d 36, reducing milk volume by $1.6 \mathrm{~L} / \mathrm{d}$. From d 41 onward, milk was no longer provided.

\section{Testing}

Tests were chosen to measure calf reactivity to environmental and social novelty. Testing started when calves were approximately $65 \mathrm{~d}$ of age. Repeated exposure provides a method for assessing habituation to the test, so calves were tested daily (from 0900 to 1230 h) for 3 consecutive days for the environmental novelty test. The social novelty test was performed on the $\mathrm{d} 4$ and 5 (from 1000 to $1030 \mathrm{~h}$ ). Calves were examined by a veterinarian on a daily basis and none showed signs of disease on any test day. For all tests, calves were walked 
to a test arena with concrete flooring (covered with approximately $3 \mathrm{~cm}$ of sawdust bedding), measuring 30 $\times 5 \mathrm{~m}$. Feces and soiled bedding were removed from the test arena after each calf was tested.

For the environmental novelty test, each replication consisted of testing calves from all 4 treatments $(8$ calves/replication) alone in the arena, once per day over $3 \mathrm{~d}$ following a randomized testing order. For the social novelty test (individual vs. pair housing), we selected 3 calves ( 1 from the individual housing treatment, 1 from the pair housing treatment, and 1 calf from the group of similar age) of similar weight from each of the 6 replications. The calf from the group of similar age (a nonfocal calf; data from this calf was not included in the analysis) was the unfamiliar calf for both individually housed (focal calf; tested once) and pair-housed calves (focal calf; tested once). The unfamiliar calf was tested twice over d 4 and 5, and treatment order was alternated for each replication. For the social novelty test (calves housed with an older companion vs. calves housed in groups of similar age), 4 calves from each of the 6 replications (all focal calves, each tested once) from both treatments were tested on d 4 and 5 . Within each replicate, a calf from one treatment was used as an unfamiliar test calf for the other treatment, and vice versa. All of the calves used in these tests had been previously habituated to the test arena for $3 \mathrm{~d}$ during the novel environment testing. All of the unfamiliar calves had been group-housed calves (either housed with an older companion or housed in groups of similar age) before testing.

Behavior of each focal calf in both tests was video recorded continuously for the 900-s test using camcorders (DCRSR100 HDD Handycam Camcorders; Sony Corp., Park Ridge, NJ). Video recordings were analyzed continuously by 1 trained observer blind to treatment using Observer software (Noldus Inc., Wageningen, the Netherlands), starting when the focal calf's back legs entered the arena. Interobserver reliability was evaluated for all behaviors studied by comparing records with a second trained observer blind to treatment in 16 environmental novelty and social novelty tests; correlations averaged $( \pm \mathrm{SD}) 0.78 \pm 0.07$. Intraobserver reliability was carried out by comparing records assessed independently by the same observer, again for both environmental and social novelty tests 16 times; correlations averaged $( \pm \mathrm{SD}) 0.89 \pm 0.05$.

Environmental Novelty Test. Behaviors recorded were time (s) spent standing inactive, walking, running, exploring [i.e., sniffing or licking (or both) the walls and floor of the arena while standing or walking], and number of defecation bouts, backing-off events (i.e., an abrupt movement in a reverse direction from the area being explored or a sudden neck movement such as a startle reflex while exploring, or both), and vocalizations. Calves were separated from their group mates during testing, so responses may have also reflected the effects of physical separation from pen mates. To assess the effect of separation, we also recorded vocalizations by the companion calves that remained in the home pens (including the older companion). Test calves were not in visual contact with their pen mates while in the test arena but the calves were able to hear one another.

Social Novelty Test. Behaviors recorded included all those described above as well as time (s) involved in social interactions with the unfamiliar calf [i.e., licking or sniffing (or both) the unfamiliar calf while standing or walking] and latency to initiate social interaction, as well as number of head-head contacts, kicks (directed by the focal calf toward the unfamiliar calf), and synchronous running events (focal calf starting a running bout within $1 \mathrm{~s}$ of the start of a bout by the unfamiliar calf).

\section{Statistical Analyses}

Durations and numbers of behaviors were summed per test and averaged for the similarly aged calves in each pen (i.e., 1 calf in the individual treatment, the 2 calves in the pair treatment, the 3 calves in the same aged treatment, and the 2 similarly aged calves in groups with an older calf), yielding a total of 72 observations for the environmental novelty test ( 6 pens for each of 4 treatments, tested over $3 \mathrm{~d}$ ) and $48 \mathrm{ob}-$ servations for the social novelty test $(6$ pens for each of 4 treatments, tested over $2 \mathrm{~d}$; 12 of these observations were not included in the analysis, as they were originated from the unfamiliar calf used in the test for the pair and individually housed calves). The effect of treatment was tested using the MIXED procedure in SAS (version 9.2; SAS Institute Inc., Cary, NC) with an autoregressive covariance structure. The model specified day as a repeated measure and pen as the subject. Residuals from the model were plotted against the predicted values to verify assumptions of normality and homogeneity of variance. All data reported met these assumptions. Specified contrasts were used to compare (1) individually housed with pair-housed calves and (2) calves of similar age with calves housed with an older companion. For all results, we report the mean value of each behavior/test if no effect of day was found. When an effect of day was found, we report the mean value for each of the test days. Day by treatment interactions were tested but never significant and, hence, are not reported below. During the social novelty test calves did not perform backing-off events so this variable is not reported below. Unless specified otherwise, means are reported \pm standard error of the mean. 
Table 1. Behavioral responses (mean \pm SEM) of individually housed ( $n=6$ calves) compared with pairhoused calves $(\mathrm{n}=6$ pairs) during the environmental and social novelty tests

\begin{tabular}{|c|c|c|c|c|}
\hline Test & Individual & Pair & SEM & $P$-value \\
\hline \multicolumn{5}{|l|}{ Environmental novelty test } \\
\hline Exploring (s/test) & 531.9 & 470.2 & 38.6 & 0.06 \\
\hline Standing (s/test) & 201.4 & 280.3 & 30.5 & 0.03 \\
\hline Walking (s/test) & 81.5 & 92.2 & 16.2 & 0.41 \\
\hline Running (s/test) & 83.2 & 57.3 & 19.1 & 0.03 \\
\hline Defecation (no./test) & 1.3 & 0.6 & 0.2 & 0.0002 \\
\hline Cautious exploration (no./test) & 4.7 & 1.6 & 0.1 & 0.0007 \\
\hline Vocalizations (no./test) & 7.7 & 14.3 & 3.0 & 0.03 \\
\hline \multicolumn{5}{|l|}{ Social novelty test } \\
\hline Exploring (s/test) & 262.1 & 358.2 & 22.1 & 0.0007 \\
\hline Standing (s/test) & 302.2 & 232.2 & 30.2 & 0.07 \\
\hline Walking (s/test) & 153.3 & 133.8 & 20.7 & 0.52 \\
\hline Running (s/test) & 51.8 & 96.4 & 11.6 & 0.02 \\
\hline Social interactions (s/test) & 130.7 & 79.7 & 19.0 & 0.05 \\
\hline Latency to socially interact ( $\mathrm{s} /$ test) & 111.1 & 20.4 & 21.7 & 0.0093 \\
\hline Defecation (no./test) & 2.3 & 0.7 & 0.5 & 0.05 \\
\hline Head-head (no./test) & 2.2 & 18.0 & 4.4 & 0.04 \\
\hline Kicks (no./test) & 2.2 & 0.7 & 0.4 & 0.03 \\
\hline Vocalizations (no./test) & 1.3 & 6.0 & 1.3 & 0.05 \\
\hline Synchronous running (no./test) & 0.5 & 1.8 & 0.4 & 0.04 \\
\hline
\end{tabular}

\section{RESULTS}

\section{Individual Versus Pair Housing}

Environmental Novelty Test. During the environmental novelty test, individually housed calves were more active than pair-housed calves as shown by less time spent standing and more time running (Table 1). The time calves spent running decreased over the 3 test days from an average of $136 \mathrm{~s}$ on $\mathrm{d} 1$ to $41 \mathrm{~s}$ on $\mathrm{d} 3$ $( \pm 19.1 \mathrm{~s} ; P<0.0001)$.

Individually housed calves were also more reactive than pair-housed calves during this test, as indicated by the increased rates of defecation and a higher number of backing-off events. Rates of defecation and backingoff events were higher on $\mathrm{d} 1$ than on subsequent days. Defecation events averaged 1.6 events on $\mathrm{d} 1$ and 0.6 events on d 3 ( \pm 0.2 events; $P<0.0001)$. Backing-off events averaged 4.7 events on $\mathrm{d} 1$ and 2.3 events on $\mathrm{d}$ 3 ( \pm 0.1 events; $P=0.03$ ). These effects of day suggest that calves habituated to the test arena. Pair-housed calves vocalized more frequently during the test, likely in response to separation from their pen mate.

Social Novelty Test. Calves housed individually explored less, ran less, and tended to spend more time standing inactive than did calves housed in pairs. Individually housed calves also showed a longer latency to initiate a social interaction (i.e., lick or sniff, or both) with the unfamiliar calf, but once social interaction was initiated, these calves were more persistent. Individually housed calves also performed fewer head-head contacts, kicked and defecated more, vocalized, and initiated fewer synchronous running events than did calves housed in pairs.

\section{Groups Housed with an Older Companion Versus Groups of Similar Age}

Environmental Novelty Test. No effect of treatment was observed on time spent running (Table 2), but there was an effect of day. Running decreased over the 3 test days from an average of $113 \mathrm{~s}$ on $\mathrm{d} 1$ to 35 $\mathrm{s}$ on d $3( \pm 12.4 \mathrm{~s} ; P<0.0001)$. Calves housed with an older companion defecated more frequently and tended to spend less time exploring and more time standing than did calves housed with same-aged group mates.

During this test, calves housed with an older companion vocalized more than did calves housed in groups of similar age (Figure 1; Table 2). When one calf was tested in the test arena, the calves that remained in the home pen sometimes vocalized. The rate of these vocalizations was higher for young calves housed with an older companion versus calves housed with similarly aged calves ( 3.7 vs. $0.5 \pm 0.7$ events/test; $P=0.0013$ ). The older social companion was also vocal, averaging ( \pm SD) $11.2 \pm 9.2$ calls/test.

Social Novelty Test. Calves housed with an older companion spent less time exploring the arena and tended to stand more than did calves housed in groups of similar age. Calves housed with an older companion kicked less frequently at the unfamiliar calf and tended to perform fewer head-head contacts than did calves housed in groups of similar age. 


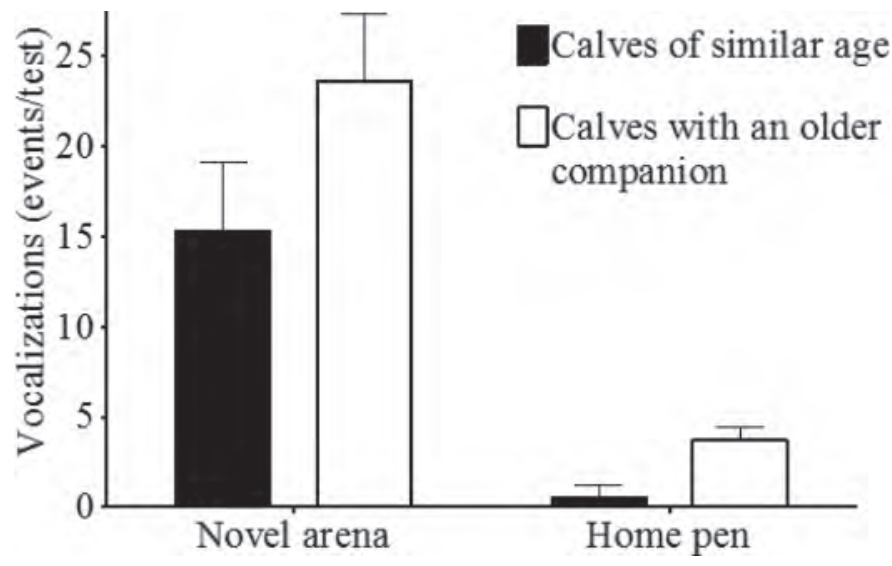

Figure 1. Number of vocalizations (mean \pm SEM; events/test) during the environmental novelty test and in the home pen for younger calves housed with an older companion $(\mathrm{n}=6$ pens) compared with calves housed in groups of similar age $(\mathrm{n}=6$ pens $)$.

\section{DISCUSSION}

\section{Individual Versus Pair Housing}

Individually housed calves were more reactive during the environmental novelty test, as indicated by more time spent standing and running and a tendency to spend more time exploring the arena, and more defecation and backing-off events during exploration relative to calves housed in pairs. These findings agree with previous work on laboratory animals (e.g., Sahakian et al., 1977; Gentsch et al., 1988; Hall et al., 1997; Varty et al., 2000) and calves (Warnick et al., 1977; Jensen et al., 1997; Jensen et al., 1999) that reported a higher sensitivity to a novel environment for individually reared animals. Isolation-syndrome-like behaviors are thought to arise because socially deprived animals overreact to novel environmental stimuli, perhaps because of heightened anxiety or emotionality (e.g., Koch and Arnold, 1972; Sahakian et al., 1977) associated with changes in brain development (Suomi et al., 1971; Schrijver and Würbel, 2001; Lipkind et al., 2002; Schrijver et al., 2002).

An alternative explanation for the increased reactivity of individually housed calves is that access to the test arena may have been more rewarding for these calves. Research on laboratory animals has shown that isolation enhances the effects of reward-related stimuli (Jones et al., 1990). The home pens of the individually housed calves were half the size of those used for the pair-housed calves, reducing the opportunity for locomotory play, perhaps making access to the large test arena particularly valuable for these calves. Calves from both conditions spent a considerable portion of their time running in the test arena, especially on the first day of testing, a result consistent with previous work on the effect of access to space on locomotory play (e.g., Dellmeier et al., 1985; Jensen, 2001; Sisto and Friend, 2001).

The results of the social novelty test showed that individually housed calves were more reactive to the

Table 2. Behavioral responses (mean \pm SEM) of younger calves housed with an older companion $(\mathrm{n}=6$ pens) compared with calves housed in groups of similar age $(n=6$ pens) during the environmental and social novelty tests

\begin{tabular}{|c|c|c|c|c|}
\hline Test & $\begin{array}{l}\text { Calves with } \\
\text { an older } \\
\text { companion }\end{array}$ & $\begin{array}{l}\text { Calves } \\
\text { of similar } \\
\text { age }\end{array}$ & SEM & $P$-value \\
\hline \multicolumn{5}{|l|}{ Environmental novelty test } \\
\hline Exploring (s/test) & 355.9 & 415.7 & 38.4 & 0.07 \\
\hline Standing (s/test) & 390.0 & 325.1 & 37.6 & 0.06 \\
\hline Walking (s/test) & 87.2 & 97.6 & 15.6 & 0.51 \\
\hline Running (s/test) & 67.0 & 61.5 & 12.4 & 0.63 \\
\hline Defecation (no./test) & 1.0 & 0.6 & 0.2 & 0.03 \\
\hline Cautious exploration (no./test) & 0.4 & 0.7 & 0.3 & 0.78 \\
\hline Vocalizations (no./test) & 23.6 & 15.3 & 3.8 & 0.0097 \\
\hline \multicolumn{5}{|l|}{ Social novelty test } \\
\hline Exploring (s/test) & 266.3 & 355.0 & 27.4 & 0.02 \\
\hline Standing (s/test) & 364.8 & 272.6 & 39.3 & 0.06 \\
\hline Walking (s/test) & 109.6 & 128.4 & 20.1 & 0.85 \\
\hline Running (s/test) & 79.4 & 72.6 & 26.7 & 0.63 \\
\hline Social interactions (s/test) & 79.9 & 71.4 & 18.6 & 0.53 \\
\hline Latency to socially interact (s/test) & 40.6 & 38.4 & 19.6 & 0.9 \\
\hline Defecation (no./test) & 0.9 & 0.7 & 0.3 & 0.57 \\
\hline Head-head (no./test) & 3.5 & 7.3 & 1.3 & 0.06 \\
\hline Kicks (no./test) & 0.1 & 2.0 & 0.5 & 0.02 \\
\hline Vocalizations (no./test) & 11.9 & 12.8 & 2.4 & 0.7 \\
\hline Synchronous running (no./test) & 2.2 & 1.8 & 0.8 & 0.6 \\
\hline
\end{tabular}


unfamiliar calf, as evidenced by increased defecation and less time spent running and exploring the arena. These calves also showed reduced synchronous running, fewer head-head contacts, and an increased latency to initiate social interactions. These results are consistent with previous work showing deficits in social behavior for calves reared individually (e.g., Veissier et al., 1994; Jensen et al., 1997, 1999). It is not clear if these deficits in social behavior decrease with social experience later in life; we encourage future research on the ontogeny of social behaviors in dairy calves.

\section{Groups Housed with an Older Companion Versus Groups of Similar Age}

To our knowledge, this is the first study to test the effects of housing calves with an older companion on responses to environmental and social novelty. Calves reared in groups with an older companion vocalized more frequently when in the test arena than did calves housed in groups of a similar age. Pen mates housed with an older companion also vocalized more in the home pen while their companion was being tested than did pen mates of calves housed in groups of similar age. Vocalizations in this context are likely an indicator of separation distress, analogous to the vocal responses of calves after separation from the dam (e.g., Flower and Weary, 2001). If this interpretation is correct, then these results suggest that calves reared with an older companion form stronger social bonds with their pen mates, perhaps especially the older calf and vice versa. Calves may have also been responding the high rates of vocalizations produced by the older companion calf. Higher separation responses by these calves might also explain the increased rates of defecation.

When introduced to an unfamiliar calf in the social novelty test, calves reared in same aged groups were more reactive than calves housed in groups with an older companion; specifically, these calves were more likely to kick at the unfamiliar calf and to engage in headhead interactions. Previous studies comparing animals that were housed with the dam with artificially reared animals reported reduced aggression among mothered animals (Seay and Harlow, 1965; Winslow, 2005) as well as higher dominance later in life (Bouissou et al., 2001); the results of the current study suggest that rearing calves with older companions may have similar effects. We especially encourage research that tests if social relationships with the older companions are aversive or not for the young calves, as the types of social interaction early in life (e.g., rejection and aggression) are known to also affect neurological development (e.g., Maestripieri et al., 1997, 1999, 2005). For example, evidence exists that in adulthood, offspring from nur- turing mothers have increased hippocampal synaptic density and enhanced performance in paradigms that test hippocampal-dependent learning and memory (Liu et al., 2000; Bredy et al., 2003a,b), whereas the neurons of offspring from less nurturing mothers are more vulnerable to apoptosis (Weaver et al., 2004, 2006).

\section{CONCLUSIONS}

Calves are typically reared individually. Preventing access to more complex social environments may leave calves less able to cope with novelty, stressful events, and perhaps especially social interactions. Calves housed individually are more reactive to environmental and social novelty when compared with calves housed in pairs. Rearing calves with an older companion appears to strengthen the social bonding within the group and may have additional benefits in terms of the development of social behavior. More research is required on the longer-term effects of the early social environment and the degree that these effects can be reversed via social experience later in life.

\section{ACKNOWLEDGMENTS}

We thank the various students at the UNBC Dairy Centre who helped in this experiment, especially Beatrice M. Lima, Laura B. Lins, and Sara Wood. We also thank Jeff Rushen (Agriculture and Agri-Food Canada, Agassiz, BC, Canada) for his input on the randomization procedures. A. De Paula Vieira was sponsored by the Capes Foundation (Ministry of Education, Brazil). The research was supported by Canada's Natural Sciences and Engineering Research Council (Ottawa, ON, Canada) via a Discovery Grant to D. M. Weary and the Industrial Research Chair Program with industry contributions from the Dairy Farmers of Canada (Ottawa, ON, Canada), Westgen Endowment Fund (Milner, BC, Canada), Pfizer Animal Health (Kirkland, QC, Canada), BC Cattle Industry Development Fund (Kamloops, BC, Canada), the BC Milk Producers (Burnaby, BC, Canada), BC Dairy Foundation (Burnaby, BC, Canada), BC Dairy Education and Research Association (Abbotsford, BC, Canada), and Alberta Milk (Edmonton, AB, Canada).

\section{REFERENCES}

Bouissou, M.-F., A. Boissy, P. Le Neindre, and I. Veissier. 2001. The social behaviour of cattle. Pages 113-145 in Social Behavior in Farm Animals. L. J. Keeling and H. W. Gonyou, ed. CABI Publishing, Wallingford, Oxon, UK and New York, NY.

Bredy, T. W., R. J. Grant, D. L. Champagne, and M. J. Meaney. 2003a. Maternal care influences neuronal survival and in the hippocampus of the rat. Eur. J. Neurosci. 18:2903-2909. 
Bredy, T. W., R. A. Humpartzoomian, D. P. Cain, and M. J. Meaney. 2003b. Partial reversal of the effect of maternal care on cognitive function through environmental enrichment. Neuroscience 118:571-576

De Paula Vieira, A., M. A. G. von Keyserlingk, and D. M. Weary. 2010. Effects of pair versus single housing on performance and behavior of dairy calves before and after weaning from milk. J. Dairy Sci. 93:3079-3085.

De Paula Vieira, A., M. A. G. von Keyserlingk, and D. M. Weary. 2012. Presence of an older weaned companion influences feeding behavior and improves performance of dairy calves before and after weaning from milk. J. Dairy Sci. 95:3218-3224.

Dellmeier, G. R., T. H. Friend, and E. E. Gbur. 1985. Comparison of four methods of calf confinement. II. Behavior. J. Anim. Sci. 60:1102-1109.

Flower, F. C., and D. M. Weary. 2001. Effects of early separation on the dairy cow and calf: 2 . Separation at 1 day and 2 weeks after birth. Appl. Anim. Behav. Sci. 70:275-284.

Fowler, C. D., Y. Liu, C. Ouimet, and Z. Wang. 2002. The effects of social environment on adult neurogenesis in the female prairie vole. J. Neurobiol. 51:115-128

Gentsch, C., M. Lichtsteiner, H.-R. Frischknecht, H. Feer, and B. Siegfried. 1988. Isolation-induced locomotor hyperactivity and hypoalgesia in rats are prevented by handling and reversed by resocialization. Physiol. Behav. 43:13-16.

Hall, F. S., T. Humby, L. S. Wilkinson, and T. W. Robbins. 1997. The effects of isolation-rearing on preference by rats for a novel environment. Physiol. Behav. 62:299-303.

Jensen, M. B. 2001. A note on the effect of isolation during testing and length of previous confinement on locomotor behavior during open-field test in dairy calves. Appl. Anim. Behav. Sci. 70:309315.

Jensen, M. B., L. Munksgaard, L. Mogensen, and C. C. Krohn. 1999. Effects of housing in different social environments on open-field and social responses of female dairy calves. Acta Agric. Scand. A Anim. Sci. 49:113-120.

Jensen, M. B., K. S. Vestergaard, C. C. Krohn, and L. Munksgaard. 1997. Effect of single versus group housing and space allowance on responses of calves during open-field tests. Appl. Anim. Behav. Sci. $54: 109-121$

Jones, G. H., C. A. Marsden, and T. W. Robbins. 1990. Increased sensitivity to amphetamine and reward-related stimuli following social isolation in rats: Possible disruption of dopamine-dependent mechanisms of the nucleus accumbens. Psychopharmacology (Berl.) 102:364-372.

Koch, M. D., and W. J. Arnold. 1972. Effects of early social deprivation on emotionality in rats. J. Comp. Physiol. Psychol. 78:391-399.

Lipkind, D., F. Nottebohm, R. Rado, and A. Barnea. 2002. Social change affects the survival of new neurons in the forebrain of adult songbirds. Behav. Brain Res. 133:31-43.

Liu, D., J. Diorio, J. C. Day, D. D. Francis, and M. J. Meaney. 2000. Maternal care, hippocampal synaptogenesis and cognitive development in rats. Nat. Neurosci. 3:799-806.

Maestripieri, D., S. G. Lindell, A. Ayala, P. W. Gold, and J. D. Higley 2005. Neurobiological characteristics of rhesus macaque abusive mothers and their relation to social and maternal behavior. Neurosci. Biobehav. Rev. 29:51-57.

Maestripieri, D., M. Tomaszycki, and K. A. Carroll. 1999. Consistency and change in the behavior of rhesus macaque abusive mothers with successive infants. Dev. Psychobiol. 34:29-35.
Maestripieri, D., K. Wallen, and K. A. Carroll. 1997. Infant abuse runs in families of group living pigtail macaques. Child Abuse Negl. $21: 465-471$.

Mirza, S. N., and F. D. Provenza. 1992. Effects of age and conditions of exposure on maternally mediated food selection in lambs. Appl. Anim. Behav. Sci. 33:35-42.

Murphey, R. M., M. J. R. Paranhos da Costa, and R. G. da Silva. 2000. Creche composition in a group of Angus calves. In Proceedings of the 34th International Congress of the ISAE, Florianapólis, Brazil. A. Ramos, L. C. Pinheiro Machado Filho, and M. J. Hötzel, ed. UFSC, Florianopolis, Brazil.

Price, E. O. 1985. Sexual behavior of large domestic farm animals: An overview. J. Anim. Sci. 61(Suppl. 3):62-74.

Sahakian, B. J., T. W. Robbins, and S. D. Iversen. 1977. The effects of isolation rearing on exploration in the rat. Anim. Learn. Behav. 5:193-198.

Sato, S., D. G. M. Wood-Gush, and G. Wetherill. 1987. Observations on creche behavior in suckler calves. Behav. Processes 15:333-343.

Schrijver, N. C. A., N. I. Bahr, I. C. Weiss, and H. Würbel. 2002. Dissociable effects of isolation rearing and environmental enrichment on exploration, spatial learning and HPA activity in adult rats. Pharmacol. Biochem. Behav. 73:209-224.

Schrijver, N. C. A., and H. Würbel. 2001. Early social deprivation disrupts attentional, but not affective, shifts in rats. Behav. Neurosci. 115:437-442

Seay, B., and H. F. Harlow. 1965. Maternal separation in the rhesus monkey. J. Nerv. Ment. Dis. 140:434-441.

Sisto, A. M., and T. H. Friend. 2001. The effect of confinement on motivation to exercise in young dairy calves. Appl. Anim. Behav. Sci. 73:83-91.

Suomi, S. J., H. F. Harlow, and S. D. Kimball. 1971. Behavioral effects of prolonged partial social isolation in the rhesus monkey. Psychol. Rep. 29:1171-1177.

Varty, G. B., M. P. Paulus, D. L. Braff, and M. A. Geyer. 2000. Environmental enrichment and isolation rearing in the rat: Effects on locomotor behavior and startle response plasticity. Biol. Psychiatry $47: 864-873$

Veissier, I., V. Gesmier, P. Le Neindre, J. Y. Gautier, and G. Bertrand. 1994. The effects of rearing in individual crates on subsequent social behavior of veal calves. Appl. Anim. Behav. Sci. 41:199-210.

Vickers, K. A., L. Niel, L. M. Kiehlbauch, and D. M. Weary. 2005. Calf response to caustic paste and hot-iron dehorning using sedation with and without local anesthetic. J. Dairy Sci. 88:1454-1459.

Vitale, A. F., M. Tenucci, M. Papini, and S. Lovari. 1986. Social behavior of calves of semi-wild Maremma cattle (Bos primigenius taurus). Appl. Anim. Behav. Sci. 26:217-231.

Warnick, V. D., C. W. Arave, and C. H. Mickelsen. 1977. Effects of group, individual, and isolated rearing of calves on weight gain and behavior. J. Dairy Sci. 60:947-953.

Weaver, I. C., N. Cervoni, F. A. Champagne, A. C. D'Alessio, S. Sharma, J. R. Seckl, S. Dymov, M. Szyf, and M. J. Meaney. 2004. Epigenetic programming by maternal behavior. Nat. Neurosci. 7:847-854.

Weaver, I. C. G., M. J. Meaney, and M. Szyf. 2006. Maternal care effects on the hippocampal transcriptome and anxiety-mediated behaviors in the offspring that are reversible in adulthood. Proc. Natl. Acad. Sci. USA 103:3480-3485.

Winslow, J. T. 2005. Neuropeptides and non-human primate social deficits associated with pathogenic rearing experience. Int. J. Dev. Neurosci. 23:245-251. 